\title{
HIGH-PERFORMANCE LIQUID CHROMATOGRAPHY ANALYTICAL METHOD VALIDATION FOR GLUTARALDEHYDE AND BENZALKONIUM CHLORIDE IN DISINFECTANTS
}

\author{
BAITHA PALANGGATAN MAGGADANI, HARMITA*, MAIZURA ISFADHILA
}

Department of Pharmacy, Faculty of Pharmacy, Universitas Indonesia, Depok, 16424, Indonesia. Email: igakadeharmita@gmail.com

Received: 26 May 2018, Revised and Accepted: 02 October 2018

ABSTRACT

Objective: The aim of this study was to produce a selective, accurate, and faster high-performance liquid chromatography (HPLC) analytical method for benzalkonium chloride and glutaraldehyde in disinfectants using ultraviolet (UV)-visible detection.

Methods: Glutaraldehyde has no chromophore, so it was first derivatized using 2,4 dinitro phenylhydrazine. Acetonitrile:water (75:25) was used as the mobile phase for glutaraldehyde and acetonitrile-acetate $\mathrm{pH} 4$ (75:25) for benzalkonium chloride, both at a flow rate of $1.2 \mathrm{~mL} / \mathrm{min}$. The optimized assay was validated with respect to accuracy, precision, linearity, selectivity, limit of quantitation (LOQ), and limit of detection (LOD).

Results: The method was linear for benzalkonium chloride, with correlation coefficient of 0.9995, LOD of 14.55 ppm, and LOQ of 48.51 ppm. The correlation coefficient for glutaraldehyde was 0.9995 , with LOD of 0.49 ppm and LOQ of 1.64 ppm. Accuracy was between $98 \%$ and $102 \%$, and precision was below $2 \%$ for both the tests.

Conclusion: The HPLC analytical method for benzalkonium chloride and glutaraldehyde in disinfectants using UV-visible detection in this research was successful to produce a selective, accurate, and faster method.

Keywords: Glutaraldehyde, Benzalkonium chloride, High-performance liquid chromatography, Optimization, Validation, Disinfectant.

(C) 2018 The Authors. Published by Innovare Academic Sciences Pvt Ltd. This is an open access article under the CC BY license (http://creativecommons. org/licenses/by/4. 0/) DOI: http://dx.doi.org/10.22159/ijap.2018.v10s1.55

\section{INTRODUCTION}

Disinfectants are chemicals that can destroy or inhibit the growth of harmful microorganisms in non-spore or vegetative states [1]. They are diverse compounds with a variety of chemical structures. Glutaraldehyde and benzalkonium chloride are two examples of active substances used as disinfectants. Glutaraldehyde is used as a $2 \%$ aqueous solution, particularly in hospitals as a common means of sterilizing medical equipment [1]. Benzalkonium chloride is also widely used in disinfectant in hospitals, farms, and food \& beverages at a concentration of $0.13 \%$. It is a cationic surfactant and is widely used as a disinfectant because of its ability to denature proteins. In hospitals, a $10 \%$ solution of the benzalkonium chloride is usually diluted to $0.05-$ $0.1 \%$ and used for various types of disinfection [2].

Glutaraldehyde and benzalkonium chloride levels are determined by titration [3] where the measurement of the endpoint can be inaccurate. Therefore, it would be desirable to develop a faster, easier, and more accurate method to determine glutaraldehyde and benzalkonium chloride concentrations using high-performance liquid chromatography (HPLC).

Several quantitative HPLC assays for benzalkonium chloride have been reported, but they are time-consuming (10-20 $\mathrm{min}$ ) and use relatively long detection wavelengths ranging from 240 to $270 \mathrm{~nm}$ which reduce their sensitivity [4]. Analysis of glutaraldehyde by gas chromatography and HPLC has been compared and showed that HPLC produced good linearity, repeatability, and errors [5-8]. However, glutaraldehyde separation was time consuming (10-15 $\mathrm{min})$. Hence, it is desirable to develop an assay for benzalkonium chloride and glutaraldehyde that is faster, selective, and accurate using HPLC with ultraviolet (UV) visible detection.

\section{MATERIALS AND METHODS}

Samples

Samples used were four disinfectants commercially available: A, B, C and D. Samples A and B contain benzalkonium chloride, while C and D contain glutaraldehyde.

\section{Chemical material}

The chemicals used were $50 \%$ benzalkonium chloride (SigmaAldrich), glutaraldehyde 50\% (Sigma-Aldrich), acetonitrile pro HPLC (Merck), glacial acetic acid (Merck), sodium acetate (Merck), distilled water (Ikapharmindo), 85\% phosphoric acid (Merck), and 2,4 dinitro phenylhydrazine (DNPH, Sigma-Aldrich).

\section{Chromatographic conditions}

An LC 20AT HPLC system (Shimadzu) equipped with pumps, Sunfire ${ }^{\circledR}$ C8 columns $(250 \mathrm{~mm}$ column length, $4.6 \mathrm{~mm}$ inner diameter, and $5 \mu \mathrm{m}$ particle size), and UV-visible detector (SPD $20 \mathrm{~A}$, Shimadzu) set at $365 \mathrm{~nm}$ for glutaraldehyde and $210 \mathrm{~nm}$ for benzalkonium chloride.

\section{Method}

Preparation of DNPH solution

About $50 \mathrm{mg}$ of DNPH was weighed into a $50 \mathrm{~mL}$ volumetric flask and $0.25 \mathrm{~mL}$ of $85 \%$ phosphoric acid added followed by acetonitrile q.s. $50 \mathrm{~mL}$. The sample was shaken until dissolved.

\section{Preparation of glutaraldehyde standard solution}

Nearly $250 \mu \mathrm{L}$ of $50 \%$ glutaraldehyde standard was diluted to $100 \mathrm{~mL}$ with acetonitrile. 
Preparation of standard benzalkonium chloride solution

About $200 \mu \mathrm{L}$ of standard $50 \%$ benzalkonium chloride solution was pipetted into a $10 \mathrm{~mL}$ volumetric flask and diluted to the limit mark using a mobile phase to produce a standard $1 \%$ solution of benzalkonium chloride. This was also diluted 10 -fold further.

\section{Preparation of $0.6 \mathrm{M}$ acetate buffer solution $\mathrm{pH} 4$}

Nearly $0.6 \mathrm{M}$ acetate buffer solution $\mathrm{pH} 4.6$ was prepared by dissolving $5.4 \mathrm{~g}$ of sodium acetate in $50 \mathrm{~mL}$. $\mathrm{pH}$ adjusted to 4.6 with glacial acetic acid and then diluted with water to $100 \mathrm{~mL}$.

\section{Glutaraldehyde derivatization optimization}

About $50 \mu \mathrm{L}$ of standard glutaraldehyde solution was placed into $5 \mathrm{~mL}$ amber flasks, and 1, 2, $4 \mathrm{~mL}$ of DNPH solution was added. Acetonitrile was then added q.s. $5 \mathrm{~mL}$, and the samples were shaken to homogenize. Each solution $(20 \mu \mathrm{L})$ was injected into the HPLC and analyzed.

\section{Glutaraldehyde derivatization}

For optimal derivatization, $2 \mathrm{~mL}$ of DNPH solution was pipetted into a $5 \mathrm{~mL}$ amber flask and $50 \mu \mathrm{L}$ of $50 \%$ glutaraldehyde standard solution was added. Acetonitrile was added q.s. $5 \mathrm{~mL}$.

\section{Mobile phase selection}

Standard solutions of benzalkonium chloride and derivatized glutaraldehyde were each injected $(20 \mu \mathrm{L})$ into the HPLC and analyzed isocratically at a $1.0 \mathrm{~mL} / \mathrm{min}$ flow rate using the buffer conditions as shown in Tables 1 and 2 .

Optimum analysis conditions were assessed based on peak retention time (tR), peak sharpness, tailing factor (Tf), resolution (R), number of theoretical plates $(\mathrm{N})$, and height equivalent to a theoretical plate (HETP).

\section{Flow rate selection}

Standard solutions of benzalkonium chloride and derivatized glutaraldehyde were each injected $(20 \mu \mathrm{L})$ onto the HPLC and using optimized mobile phase compositions and run at flow rates of $0.8,1.0$, or $1.2 \mathrm{~mL} / \mathrm{min}$.

Furthermore, the most optimum analysis conditions were assessed based on peak tR, peak sharpness, Tf, R, N, and HETP.

\section{System suitability test}

Standard solutions of benzalkonium chloride and derivatized glutaraldehyde solutions were injected $(20 \mu \mathrm{L})$ onto the HPLC and run at the optimized flow rate and in the optimized mobile phases up to 6 times. Peak areas were integrated, and a relative standard deviation (RSD) of $2 \%$ or less was considered acceptable.

Table 1: Mobile phase variants for analysis benzalkonium chloride

\begin{tabular}{ll}
\hline Acetonitrile & $\mathbf{0 . 6 M}$ acetate \\
\hline 75 & 25 \\
60 & 40 \\
70 & 30 \\
\hline
\end{tabular}

Table 2: Mobile phase variants for glutaraldehyde analysis

\begin{tabular}{ll}
\hline Acetonitrile & Distilled water \\
\hline 75 & 25 \\
60 & 40 \\
80 & 20 \\
\hline
\end{tabular}

\section{Validation of analytical methods}

Glutaraldehyde calibration curve

$5,40,50,30,40$, and $50 \mu \mathrm{L}$ were placed into $5 \mathrm{~mL}$ amber flasks containing $2 \mathrm{~mL}$ DNPH and acetonitrile q.s. $5 \mathrm{~mL}$ and shaken to homogenize. $20 \mu \mathrm{L}$ of each standard solution was analyzed.

\section{Benzalkonium chloride calibration curve}

$1 \%$ benzalkonium chloride solution was diluted to $20,50,100,200$, 300 , and $400 \mu \mathrm{g} / \mathrm{mL} .20 \mu \mathrm{L}$ of each standard solution was analyzed.

\section{Detection limit test (LOD) and quantitation limit (LOQ)}

Detection and quantitation limits can be calculated statistically by linear regression of calibration curves. The calculation result will be equal to the value of $b$ in the equation $(y=a+b x)$, whereas the SD of the blank is equal to the residual SD (Sy/x) [9].

\section{Selectivity}

Selectivity was assessed using standard solutions. $20 \mu \mathrm{L}$ of each solution was injected into HPLC under the optimized analysis conditions. The observation was conducted to find if there was a difference in tR between samples and standards and if there was other peaks appeared at the time of retention of benzalkonium chloride and glutaraldehyde in the sample solution.

\section{Accuracy and precision}

Sample was prepared using the same procedure used for standard curves so as to produce low, medium, and high samples containing 80 , $100 \mu \mathrm{g} / \mathrm{mL}$, and $120 \mu \mathrm{g} / \mathrm{mL}$ of benzalkonium chloride, respectively. Similarly, 8, 10, and $12 \mu \mathrm{g} / \mathrm{mL}$ samples of glutaraldehyde were also prepared. Each sample was produced in triplicate and $20 \mu \mathrm{L}$ of each analyzed.

\section{Sample preparation}

Samples containing benzalkonium chloride (A and B)

A $1.5 \mathrm{~mL}$ aliquot sample solution then inserted into a $100 \mathrm{~mL}$ measuring flask, then dissolved and diluted with a mobile phase up to the limit mark, shake, and homogenized. $20 \mu \mathrm{L}$ was analyzed by HPLC.

\section{Samples containing glutaraldehyde ( $C$ and $D$ )}

$1.5 \mathrm{~mL}$ sample was diluted into $100 \mathrm{~mL}$ with acetonitrile and shaken to homogenize. $50 \mu \mathrm{L}$ of the solution was inserted into a $5 \mathrm{~mL}$ chrysanthemum that has been filled $2 \mathrm{~mL} \mathrm{DNPH}$ and then homogenized. $20 \mu \mathrm{L}$ was analyzed by HPLC.

\section{Sample analysis}

Each sample was treated as described above. $20 \mu \mathrm{L}$ aliquots were analyzed by HPLC and peak areas recorded. Injections were performed in duplicate.

\section{RESULTS AND DISCUSSION}

\section{Method optimization}

\section{Glutaraldehyde derivatization}

Derivatization in HPLC methods is required to transform the analyte into a form that can be detected with the required sensitivity and selectivity [10]. Glutaraldehyde is a compound with no chromophore group so that it must be derivatized with DNPH. DNPH was titrated to determine optimal derivatization conditions. Thus, 1, 2, or $4 \mathrm{~mL}$ of DNPH was added to the glutaraldehyde standard. The largest peak area was produced with $2 \mathrm{~mL}$ of DNPH, and this also yielded the highest resolution than the other volumes.

\section{Selection of mobile phase composition}

Acetonitrile-acetate $\mathrm{pH} 4$ at various ratios was used as the mobile phase for the analysis of benzalkonium chloride and to determine tR, HETP, $\mathrm{N}$, and Tf (Table 3). Based on these results obtained, the 75:25 ratio 
was chosen as the mobile phase for benzalkonium chloride because it produced the best separation and largest peak area.

For glutaraldehyde analysis, various rations of acetonitrile:water were used as the mobile phase to determine the same parameters. The 75:25 ratio was chosen because it produced a higher resolution than the 80:20 and a shorter retention than 60:40.

\section{Flow rate selection}

After optimizing the mobile phase, flow rate optimization is carried out with variations of $0.8,1.0$, and $1.2 \mathrm{~mL} / \mathrm{min}$ for both the analytes (Tables 4 and 5). Based on the results, $1.2 \mathrm{~mL} / \mathrm{min}$ was chosen for benzalkonium chloride because it produced the fasted elution while exhibiting good separation (Table 4). The same flow rate was chosen for glutaraldehyde because of the shorter retention time and the resolution did not vary substantially from the other flow rates (Table 5).

\section{System suitability test}

The suitability test of the system was performed 6 times by successive injection of standard benzalkonium chloride solution using an acetonitrile-acetate buffer phase $(75: 25)$ at a flow rate of $1.2 \mathrm{ml} / \mathrm{min}$ and a glutaraldehyde standard with an acetonitrile-water phase (75:25) at flow rate of $1.2 \mathrm{ml} / \mathrm{min}$. The benzalkonium chloride system produced an RSD of $0.55 \%$, while the glutaraldehyde method produced an RSD of $0.94 \%$, both of which were below the maximum requirement of $2 \%$.

Table 3: Relationship between retention time, tailing factor, HETP, and number of theoretical plates of benzalkonium chloride HPLC and changes in mobile phase composition

\begin{tabular}{lllll}
\hline Acetonitrile: water (75:25) & 9.351 & 0.946 & 0.0265 & 9404 \\
Acetonitrile: water (80:20) & 6.096 & 0.979 & 0.0281 & 8881 \\
Acetonitrile: water (60:40) & 27.701 & 0.999 & 0.0245 & 10163 \\
\hline
\end{tabular}

HETP: Height equivalent to a theoretical plate, HPLC: High-performance liquid chromatography

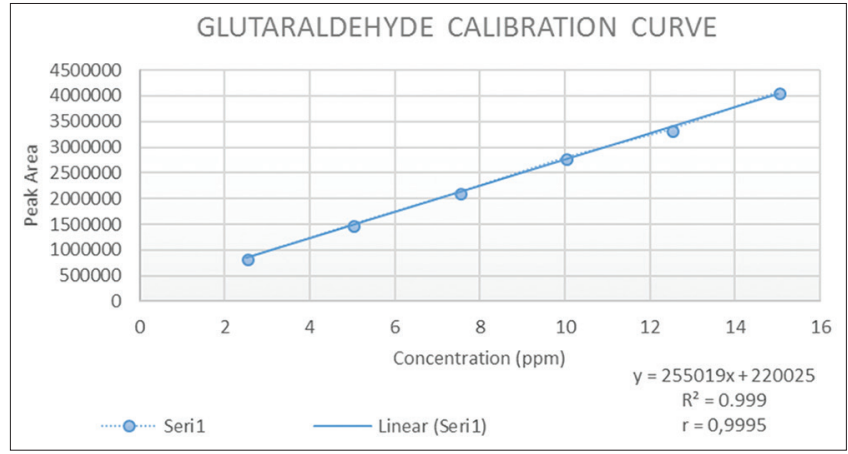

Fig. 1: Benzalkonium chloride calibration curve. The curve was produced using $2.5,5,7.5,10,12.5$, and $15 \mu \mathrm{g} / \mathrm{ml}$ benzalkonium chloride. The equation of the curve is $y=255019 x+220025$ and the correlation coefficient ( $r$ ) is 0.9995

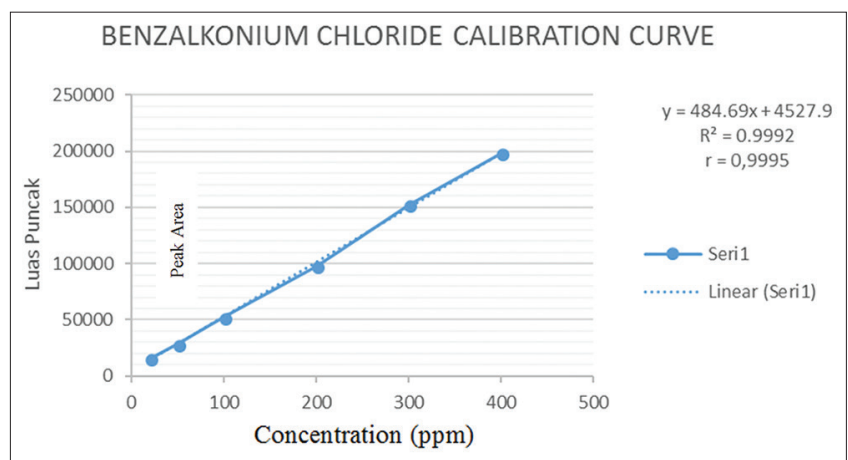

Fig. 2: Glutaraldehyde chloride calibration curve. The curve was produced using $20,50,100,200,300$, and $400 \mu \mathrm{g} / \mathrm{ml}$ glutaraldehyde. The equation of the curve is $y=484.69 x+4527.9$ and the correlation coefficient ( $r$ ) is 0.9995

Table 4: Relationship between retention time, the number of theoretical plates, the efficiency of the column, and a factor of benzalkonium chloride chromatogram on flow rate changes

\begin{tabular}{lllll}
\hline Flow rate (mL/min) & Retention time (min) & Tailing factor & HETP & Number of theoretical plates \\
\hline 0.8 & 8.003 & 2.398 & 0.0219 & 4517 \\
1.0 & 6.224 & 1.476 & 0.0254 & 2998 \\
1.2 & 4.012 & 1.478 & 0.0245 & 7466 \\
\hline
\end{tabular}

HETP: Height equivalent to a theoretical plate

Table 5: Relationship between retention time, the number of theoretical plates, the efficiency of the column, and a factor of glutaraldehyde chromatogram on flow rate changes

\begin{tabular}{|c|c|c|c|c|c|}
\hline Flow rate $(\mathrm{mL} / \mathrm{min})$ & Retention time (min) & Tailing factor & HETP & Number of theoretical plates & Resolution \\
\hline 0.8 & 9.894 & 0.945 & 0.0219 & 11392 & 2.548 \\
\hline 1.0 & 9.302 & 0.958 & 0.0254 & 9822 & 2.743 \\
\hline 1.2 & 6.634 & 0.941 & 0.0245 & 10309 & 2.442 \\
\hline
\end{tabular}

HETP: Height equivalent to a theoretical plate

Table 6: Determination of benzalkonium chloride content of sample A

\begin{tabular}{|c|c|c|c|c|c|c|}
\hline Sample & $\begin{array}{l}\text { Concentration } \\
\text { (ppm) }\end{array}$ & $\begin{array}{l}\text { Peak } \\
\text { area }\end{array}$ & $\begin{array}{l}\text { Sample } \\
\text { level (\%) }\end{array}$ & $\begin{array}{l}\text { Average sample } \\
\text { level (\%) }\end{array}$ & $\begin{array}{l}\text { Levels in } \\
\text { etiquette (\%) }\end{array}$ & $\begin{array}{l}\text { Recovery of } \\
\text { etiquette }(\%)\end{array}$ \\
\hline \multirow[t]{2}{*}{ A (benzalkonium chloride) } & 100 & 49735 & 18.65 & 19.2 & 20 & 93.2 \\
\hline & & 51539 & 19.39 & & 20 & 96.99 \\
\hline \multirow[t]{2}{*}{ B (benzalkonium chloride) } & 100 & 51533 & 9.697 & 9.678 & 10 & 96.97 \\
\hline & & 51346 & 9.659 & & 10 & 96.59 \\
\hline \multirow[t]{2}{*}{ C (glutaraldehyde content) } & 12.5 & 11713876 & 30.04 & 29.82 & 30 & 100.13 \\
\hline & & 11562123 & 29.65 & & 30 & 99.48 \\
\hline \multirow[t]{2}{*}{ D (glutaraldehyde content) } & $\mathrm{D}$ & 1528059 & 14.93 & 14.71 & 15 & 99.5 \\
\hline & & 1521606 & 14.5 & & 15 & 96.8 \\
\hline
\end{tabular}


Method validation

\section{Calibration curve}

Glutaraldehyde and benzalkonium chloride standards of various concentrations produced the calibration curve through linear regression with correlation coefficients of 0.9995 (Figs. 1 and 2). Both of these correlation coefficients met the requirements $(\geq 0.999)$.

\section{Determination of $L O D$ and $L O Q$}

Assessment of the detection and quantitation limits is necessary to ascertain the lowest level at which a substance can be reliably detected and the lowest concentration at which the levels can be determined precisely, respectively. These are determined on the basis of statistical calculations through the linear regression of the obtained from the calibration curve. The LOD for benzalkonium chloride solution was $14.5 \mu \mathrm{g} / \mathrm{mL}$ and the LOQ was $48.5 \mu \mathrm{g} / \mathrm{mL}$. In the case of glutaraldehyde, the LOD was $0.492 \mu \mathrm{g} / \mathrm{mL}$ and the LOQ was $1.640 \mu \mathrm{g} / \mathrm{mL}$.

\section{Selectivity}

This parameter relates to the extent to which other substances may interfere with the method of analysis and are a measure of the method's ability to identify or measure the analyte in the presence of other substances from the sample matrix under predefined conditions. Specificity can be determined by adding ingredients that may be present in the sample [11]

Results from injection of $20 \mu \mathrm{L}$ of glutaraldehyde in a placebo disinfectant matrix solution and also co-injection of DNPH showed no interference at the standard glutaraldehyde retention time. Likewise, no interference was found following an analysis of benzalkonium chloride in a placebo disinfectant matrix. This suggests that the method used is selective for glutaraldehyde and benzalkonium chloride compounds.

\section{Accuracy and precision}

Accuracy is the closeness between a test result and the true content of the analyte [12]. Accuracy should be performed in the same experiment using the same solution, and this parameter should be determined at three concentrations, including low, medium, and high [13]. Each level should be analyzed using three to six repetitions [14]. While good accuracy values range from $98 \%$ to $102 \%$, for biological samples, this can range as widely as $\pm 10 \%$. Accuracy can be determined both absolutely and by addition [9].

This study used the simulation or spiked-placebo method to determine accuracy and precision. In the simulation method, standards are added to the placebo (disinfecting matrix) at various concentrations and then analyzed. Analytically, the determined levels are then compared with the known levels added to the placebo to obtained values for recovery (\% R). At glutaraldehyde concentrations of 8,10 , and $12 \mu \mathrm{g} /$ $\mathrm{mL}$, recoveries were $99.049 \%, 99.415 \%$, and $99.565 \%$, respectively. For benzalkonium chloride at 80,100, and $120 \mu \mathrm{g} / \mathrm{mL}$, recoveries were $100.94 \%$, 99.928\%, and $99.974 \%$, respectively. This result met the requirements of the range of $98-102 \%$.

Precision is generally measured as the coefficient of variation or standard RSD from the repeated analysis of freshly prepared quality control standards [11]. In general, a value of $2 \%$ or less is acceptable, but this value is flexible depending on the concentration of alkylate analyzed, the number of samples tested, and the conditions in the laboratory [2].
Precision is performed by calculating the RSD of triplicate analyses sample used for accuracy determination. The data obtained here met the requirements of $\leq 2 \%$.

Determination of glutaraldehyde and benzalkonium chloride levels in disinfectant samples

Four samples consisting of two samples containing glutaraldehyde and two samples containing benzalkonium chloride were analyzed in duplicate, and the results are summarized in Tables 6

\section{CONCLUSION}

The HPLC analytical method for benzalkonium chloride and glutaraldehyde in disinfectants using UV-visible detection in this research was successful to produce a selective, accurate, and faster method.

\section{CONFLICTS OF INTEREST}

All authors have none to declare.

\section{REFERENCES}

1. Sweetman, S. Martindale. London: PhP Pharmaceutical Press; 2009.

2. Koyama K, Shimazu T. Benzalkonium Chloride. Berlin Heidelberg: Springe-Verlag; 2005. p. 407-13.

3. Directorate General of Livestock Product Development Indonesian Ministry of Agriculture. Indonesian Veterinary Drug Pharmacopoeia. Jakarta: Indonesian Ministry of Agriculture; 2008.

4. Labranche LP, Dumont SN, Levesque S, Carrier A. Rapid determination of total benzalkonium chloride content in ophthalmic formulation. J Pharm Biomed Anal 2007;43:989-93.

5. Menet MC, Gueylard D, Fievet MH, Thuillier A. Fast specific separation and sensitive quantification of bactericidal and sporicidal aldehydes by high-performance liquid chromatography: Example of glutaraldehyde determination. J Chromatogr Sep Tech 1997;692:79-86.

6. Harmita. Physicochemistry Analysis. Depok: Faculty of Pharmacy, Universitas Indonesia; 2012.

7. Rediatning W, Kartini N. Analysis of amino acids with high performance liquid chromatography derivatized prakolom and pascakolom. Proc ITB 1987;20:1-19.

8. Rao N, Gawde KD. Method development and force degradation studies for simultaneous estimation of salbutamol sulfate, etofylline and bromhexine hydrochloride in pharmaceutical dosage form using reversed-phase high-performance liquid chromatography method. Asian J Pharm Clin Res 2018;11:378-82

9. Shaikh S, Jain V. A novel reverse-phase high-performance liquid chromatographic method for simultaneous estimation of ellagic acid, quercetin, and piperine in ayurvedic formulations. Asian J Pharm Clin Res 2018;11:312-7.

10. Ramesha B, Reddy KR, Unni KM, Ankolekar V, Anuradha P, Amith KM. A validated UHPLC method for the determination of atorvastatin acetonide tert-butyl ester and 4-fluoro-alpha-(2-methyl-1oxopropyl)-gamma-oxo-n, beta-diphenylbenzene butaneamide. Asian J Pharm Clin Res 2012;5:115-22.

11. ICH. ICH Topic Q2 (R1) Validation of Analytical Procedures: Text and Methodology. International Conference on Harmonization, 1994; 1996.

12. Thompson M, Ellison SL, Wood R. Harmonized guidelines for singlelaboratory validation of methods of analysis (IUPAC Technical Report). Pure Appl Chem 2002;74:835-55.

13. Bretnall AE, Clarke GS. Validation of analytical test methods. In: Ahuja S, Scypinski S, editors. Handbook of Modern Pharmaceutical Analysis, Separation Science and Technology Series. $2^{\text {nd }}$ ed. Waltham, MA, USA: Academic Press (Elsevier); 2011. p. 9-457.

14. Anderson J, Berthod A, Pine V, Stalcup AM. Analytical Separation Science. Harlow, UK: Prentice-Hall; 2016. 